Supporting Information for

\title{
Transport Modeling of Kinetically Limited Microscale Extraction Systems: Droplet and Supported Liquid Membrane Separations
}

\author{
Anna G. Servis ${ }^{\mathrm{a}, \mathrm{b},{ }^{*}, \text { Tashi Parsons-Davis }}{ }^{\mathrm{a}}$, Kenton J. Moody ${ }^{\mathrm{a}}$, and Narek Gharibyan ${ }^{\mathrm{a}}$

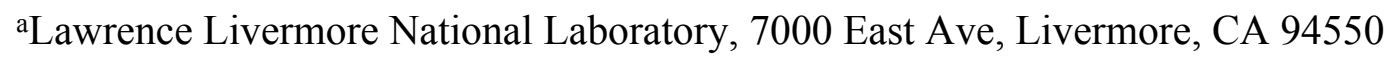

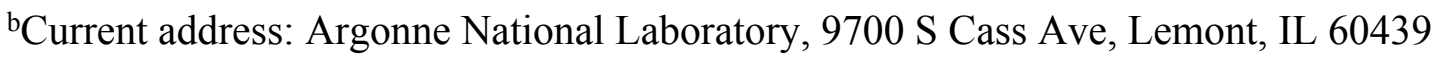 \\ *Corresponding author: aservis@anl.gov
}

\section{Table of Contents}

Droplet Surface Area-to-Volume Calculation ............................................................1

3 D Printed Phase Separator Design and Construction .................................................3

Droplet Apparatus Cost Breakdown ....................................................................4

Droplet Extraction Numerical Model ..................................................................4

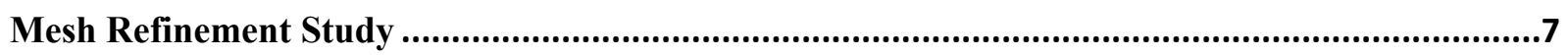

Supported Liquid Membrane Numerical Model.........................................................8

SLM Dependence on Kinetic Rate Constants...........................................................11

Incomplete Phase Separation Error Analysis..............................................................12

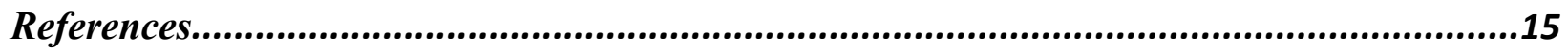

\section{Droplet Surface Area-to-Volume Calculation}

For the purpose of calculating the surface area-to-volume ratio $(A / V)$ of droplets from axial length and contact angle data, the droplets were approximated as cylinders with paraboloid caps, as shown schematically in Figure S1.

The following equations for a 1:1 organic to aqueous phase ratio were used:

$$
\begin{gathered}
\text { contact angle }=\theta(>\pi / 2) \\
h=\frac{r_{t} \tan (\theta-\pi / 2)}{2}
\end{gathered}
$$




$$
\begin{gathered}
\text { droplet volume }=V=\frac{\pi r_{t}{ }^{2}\left(l_{a q}+l_{\text {org }}\right)}{2} \\
l_{a q}=\frac{V-\pi r_{t}{ }^{2} h}{\pi r_{t}{ }^{2}}+2 h \\
l_{\text {org }}=\frac{V-\pi r_{t}{ }^{2} h}{\pi r_{t}{ }^{2}} \\
\text { interfacial surface area }=A=\pi r_{t}{ }^{2}+\frac{\pi r_{t}}{6 h^{2}}\left[\left(r_{t}{ }^{2}+4 h^{2}\right)^{\frac{3}{2}}-r_{t}^{3}\right]
\end{gathered}
$$

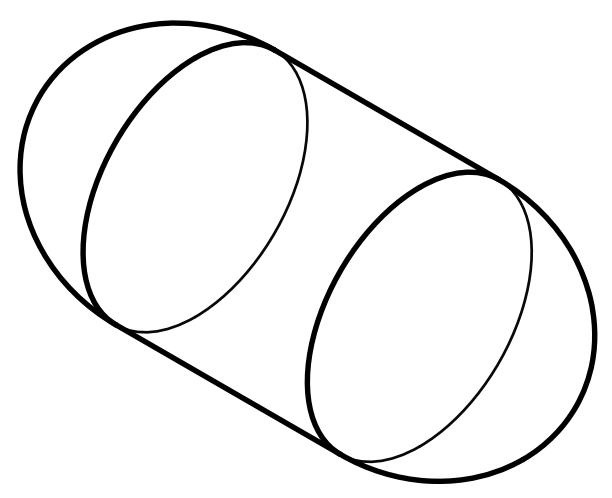

Aqueous Droplet

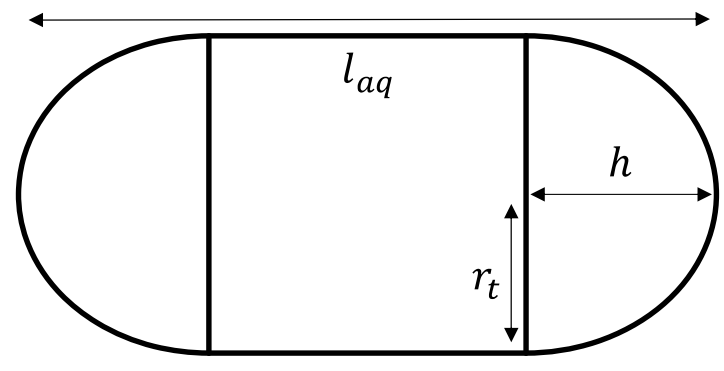

Aqueous Side View

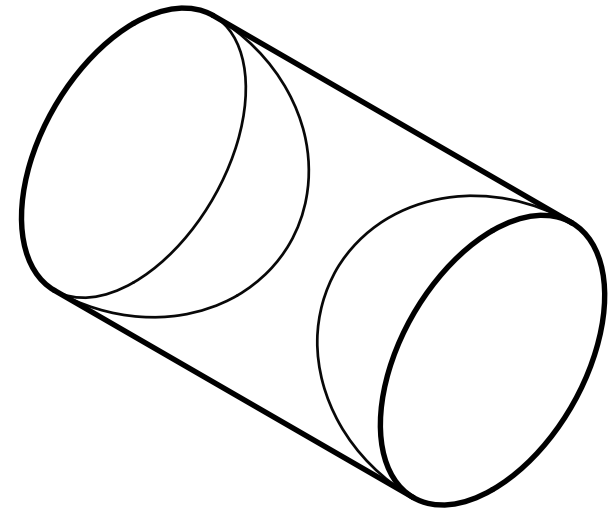

Organic Droplet

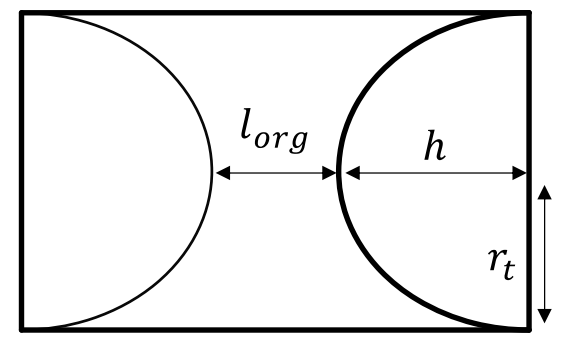

Organic Side View

Figure S1. Aqueous and organic droplet geometries (not to scale). 


\section{D Printed Phase Separator Design and Construction}

The design of the phase separator presented in this work falls into the class of miniaturized phase separators whose operation is based on capillary pressure, as described by Wang, et al. In this type of phase separator, alternating organic and aqueous droplets are separated into pure organic and aqueous streams by selective permeation of one of the phases through an array of capillary channels, here provided by a porous polytetrafluoroethylene (PTFE) membrane. Capillary pressure in the membrane pores, which have a hydrophobic surface, prevents the aqueous phase from passing through the membrane while drawing the organic phase to the other side of the membrane. The back pressure required for complete separation of the phases at high flow rates was generated by the use of $30 \mathrm{~cm}$ of PEEK capillary tubing ( $150 \mu \mathrm{m}$ inner diameter, TPK106, Valco Instruments Co. Inc.) at the aqueous phase outlet. The organic phase outlet tubing was $15 \mathrm{~cm}$ of the same 500 $\mu \mathrm{m}$ inner diameter FEP tubing used elsewhere. Viton O-rings (Grainger, Inc.) were placed at the end of each threaded connection to the 3D printed phase separator and around the membrane as indicated in Figure 1(b) of the main text to ensure liquid tightness of the apparatus.

The purpose of the droplet extraction apparatus fabricated here is to measure the kinetics of the transfer of solutes between adjacent droplets while in the droplet contact channel. Accordingly, the membrane phase separator was designed to have a small volume relative the volume of the entering contact channel to minimize the impact of the phase separation process on solute transfer between the phases. The phase separator consists of two 3D printed pieces with open $1 \mathrm{~mm}$ wide, $20.8 \mathrm{~mm}$ long, and $0.2 \mathrm{~mm}$ deep rectangular channels that align when the two pieces are fastened together. This corresponds to a total enclosed channel volume of $8.4 \mu \mathrm{L}$, or approximately $12 \%$ of the total internal volume of the apparatus from the droplet-generating junction to the end of the phase separator. During use, a $25 \mathrm{~mm}$ diameter PTFE membrane $(0.2 \mu \mathrm{m}$ pore size, $74 \%$ porosity, T020A025A, Advantec MFS, Inc) was placed between the two open channels. The two 3D printed halves of the channel were clamped together by four 10-24 18-8 stainless steel machine screws and matching nuts in a flange surrounding the channel and membrane. Sockets to contain the nuts and through-holes for the screws were included in this flange in the 3D printed design, as indicated in Figure 1(b) of the main text. Details of the design and printing process are described in our previous work (Servis, et al. 2021). High temp resin was used to 3D print the phase separator on a Form 2 3D printer (Formlabs, Inc.) due to its high chemical resistance after the manufacturerrecommended cleaning and post-cure steps. 


\section{Droplet Apparatus Cost Breakdown}

Table S1. Detailed cost breakdown of droplet extraction apparatus.

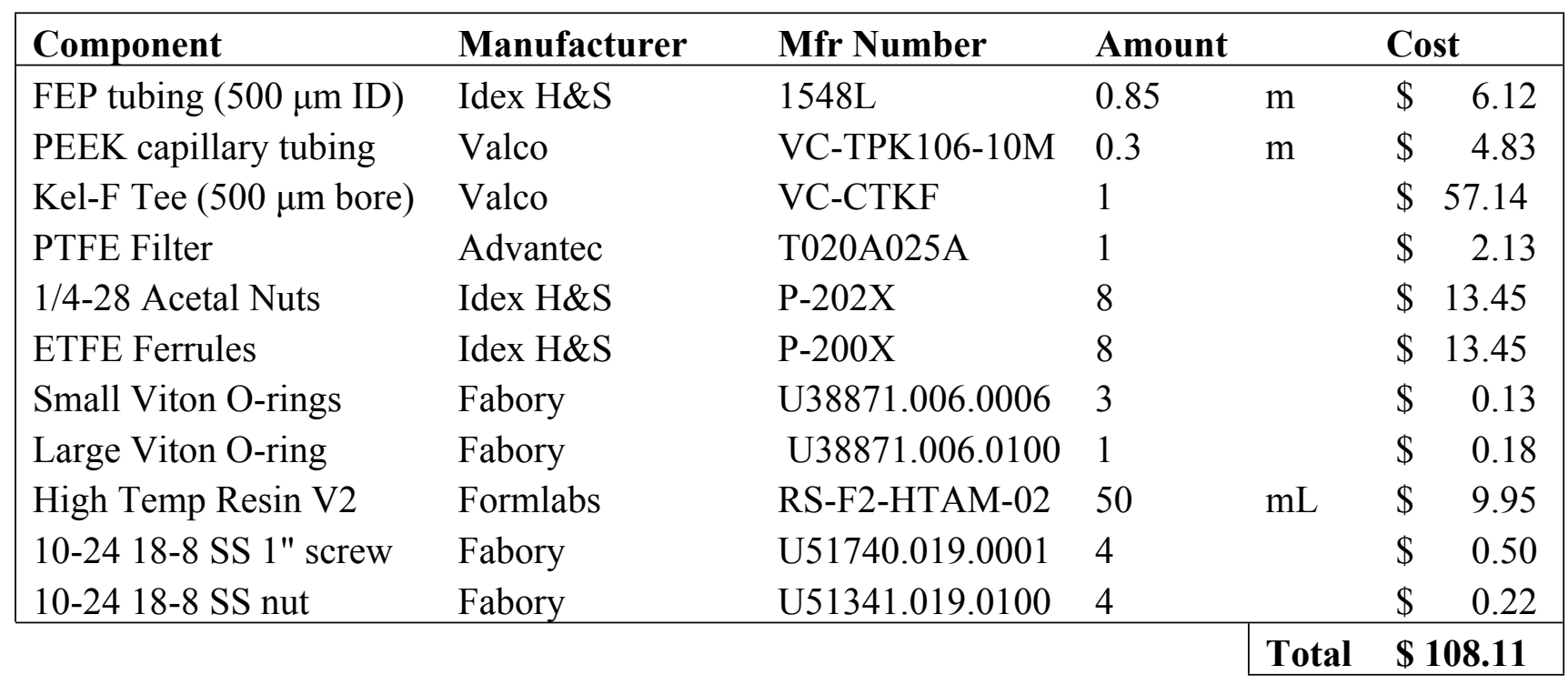

\section{Droplet Extraction Numerical Model}

The droplet extraction numerical model geometry referred to in the body of this manuscript is shown in Figure S2 for a system with a $250 \mu \mathrm{m}$ tubing radius $\left(r_{t}\right)$ and $235 \mathrm{~nL}$ alternating organic and aqueous droplets. The relevant boundary and initial conditions are provided in Table S2. The concentration-dependent diffusion coefficient used to model kinetically limited interfacial solute transfer can be derived from the following relationship, where the organic phase is 'down' and the aqueous phase is 'up':

$$
k_{a o} C_{u}-k_{o a} C_{d}=\frac{D_{\mathrm{int}}}{a}\left(C_{u}-C_{d}\right)
$$

In this equation, $k_{a o}$ and $k_{o a}$ are the interfacial rate constants, $C_{d}$ is the solute concentration on the 'down' side of the interface, $C_{u}$ is the solute concentration on the 'up' side of the interface, $D_{\text {int }}$ is the parameter being solved for, the concentration-dependent diffusion coefficient, and $a$ is the thickness of the interface, which was set to a physically-realistic value of $5 \mathrm{~nm}$.

Additional information about the refined mesh is provided in Figures S3 and S4. 


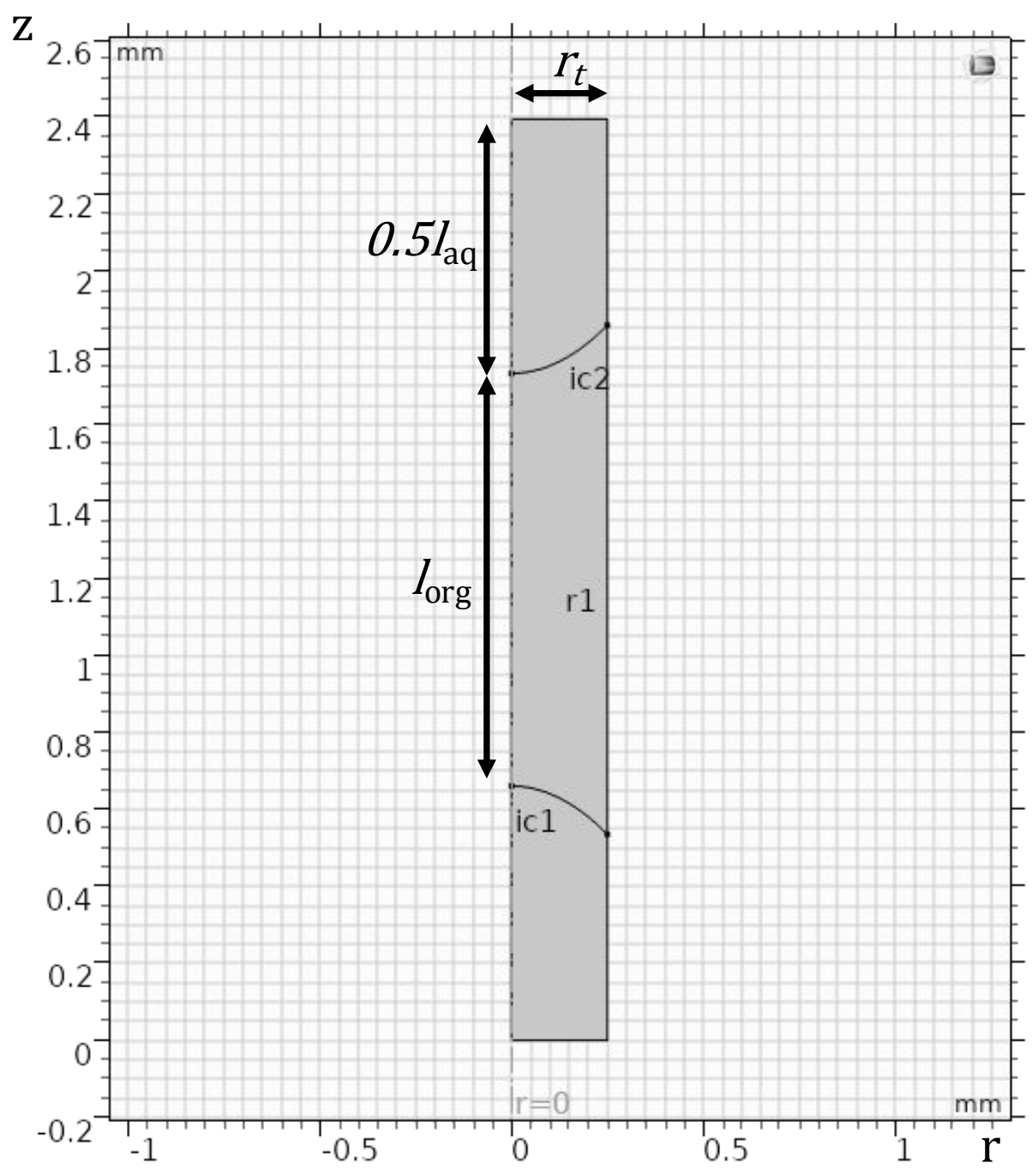

Figure S2. Geometry for the 2D droplet extraction model (250 $\mu$ m tubing radius shown). 
Table S2. Droplet extraction numerical transport model boundary and initial conditions. $C$ is concentration, $P$ is pressure, $\vec{J}$ is flux, $\vec{v}$ is velocity, $u$ is up, $d$ is down, src is source, dst is destination.

\begin{tabular}{|c|c|c|}
\hline $\begin{array}{ll}\text { Boundary } & \text { Condition } \\
\text { Description } & \end{array}$ & Limits & Condition \\
\hline Organic phase concentration & $i c 1 \leq z \leq i c 2,0 \leq r \leq r_{t}$ & $C_{0}=0$ or $1 \mathrm{mM}$ \\
\hline Aqueous phase concentration & $\begin{array}{c}0 \leq z<i c 1, i c 2<z \leq l_{\mathrm{aq}}+l_{\mathrm{org}} \\
0 \leq r \leq r_{t}\end{array}$ & $C_{0}=0$ or $1 \mathrm{mM}$ \\
\hline Tubing outlet gauge pressure & $z=0, r=r_{t}$ & $P=0 P a$ \\
\hline Periodic flow condition* & $\begin{array}{c}\quad z=0,0 \leq r \leq r_{t} \\
\text { and } \quad \begin{array}{l}z=l_{\mathrm{aq}}+l_{\mathrm{org}}, 0 \leq r \leq r_{t}\end{array}\end{array}$ & $\begin{array}{l}\underset{v_{s r c}}{C_{s r c}}=\underline{C_{d s t}} \\
\overrightarrow{v_{d s t}}\end{array}$ \\
\hline $\begin{array}{l}\text { No slip condition at moving } \\
\text { wall }\end{array}$ & $r=r_{t}, 0 \leq z \leq l_{\mathrm{aq}}+l_{\mathrm{org}}$ & $\vec{v}=$ varied \\
\hline Moving mesh interface* & $\begin{array}{l}z=i c 1,0 \leq r \leq r_{t} \\
z=i c 2,0 \leq r \leq r_{t}\end{array}$ & $\begin{array}{l}\overrightarrow{v_{i c 1}}=\text { varied } \\
\overrightarrow{v_{i c 2}}=\text { varied }\end{array}$ \\
\hline $\begin{array}{l}\text { Thin diffusion barrier at } \\
\text { interfaces* }\end{array}$ & $\begin{array}{l}\text { and } \\
\qquad \begin{array}{l}z=i c 1,0 \leq r \leq r_{t} \\
z\end{array}=i c 2,0 \leq r \leq r_{t}\end{array}$ & $\begin{array}{l}\vec{J}=\frac{D}{5[n m]}\left(C_{u}-C_{d}\right) \\
D=f\left(k_{o a}, k_{a o}, C_{u}, C_{d}\right)\end{array}$ \\
\hline No flux condition at wall & $r=r_{t}, 0 \leq z \leq l_{\mathrm{aq}}+l_{\mathrm{org}}$ & $\vec{J}=0$ \\
\hline
\end{tabular}

* Refer to COMSOL documentation for details about the moving mesh boundary condition, thin diffusion barrier boundary condition, and up/down notation at interfaces. 


\section{Mesh Refinement Study}

For a uniform mapped mesh, the calculated average concentrations in each phase were determined to be independent of the number of elements for a mesh with greater than 269,325 elements in the 0.250 by $1.197 \mathrm{~mm} 2 \mathrm{D}$ initial droplet geometry. To improve computational efficiency, the mesh was refined in the parts of the geometry with the largest gradients in concentration and velocity. A tetrahedral mesh was used in these areas, which were close to the liquid-liquid interface. The highest mesh element density was located at the points where the interface between the two phases meet the wall of the tubing (Figure S3). The solution calculated using this refined mesh was within $1 \%$ of the mesh-independent solution calculated using a uniform mapped mesh with an order of magnitude more elements (Figure S4).
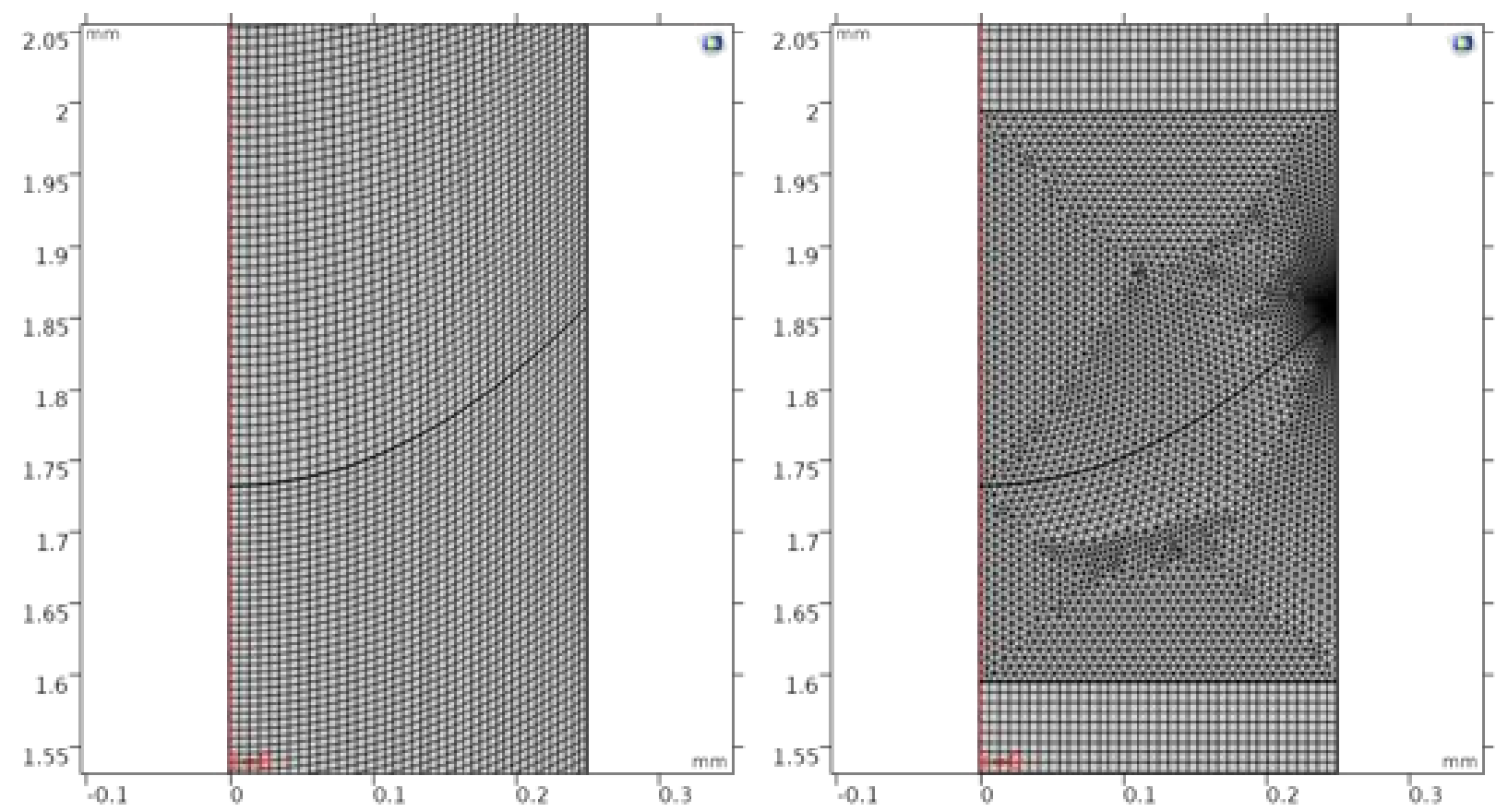

Figure S3. The mesh used to discretize the droplet extraction model was refined near the intersection of the two liquid phases with the tubing wall, where the largest gradients in concentration and velocity are located. 


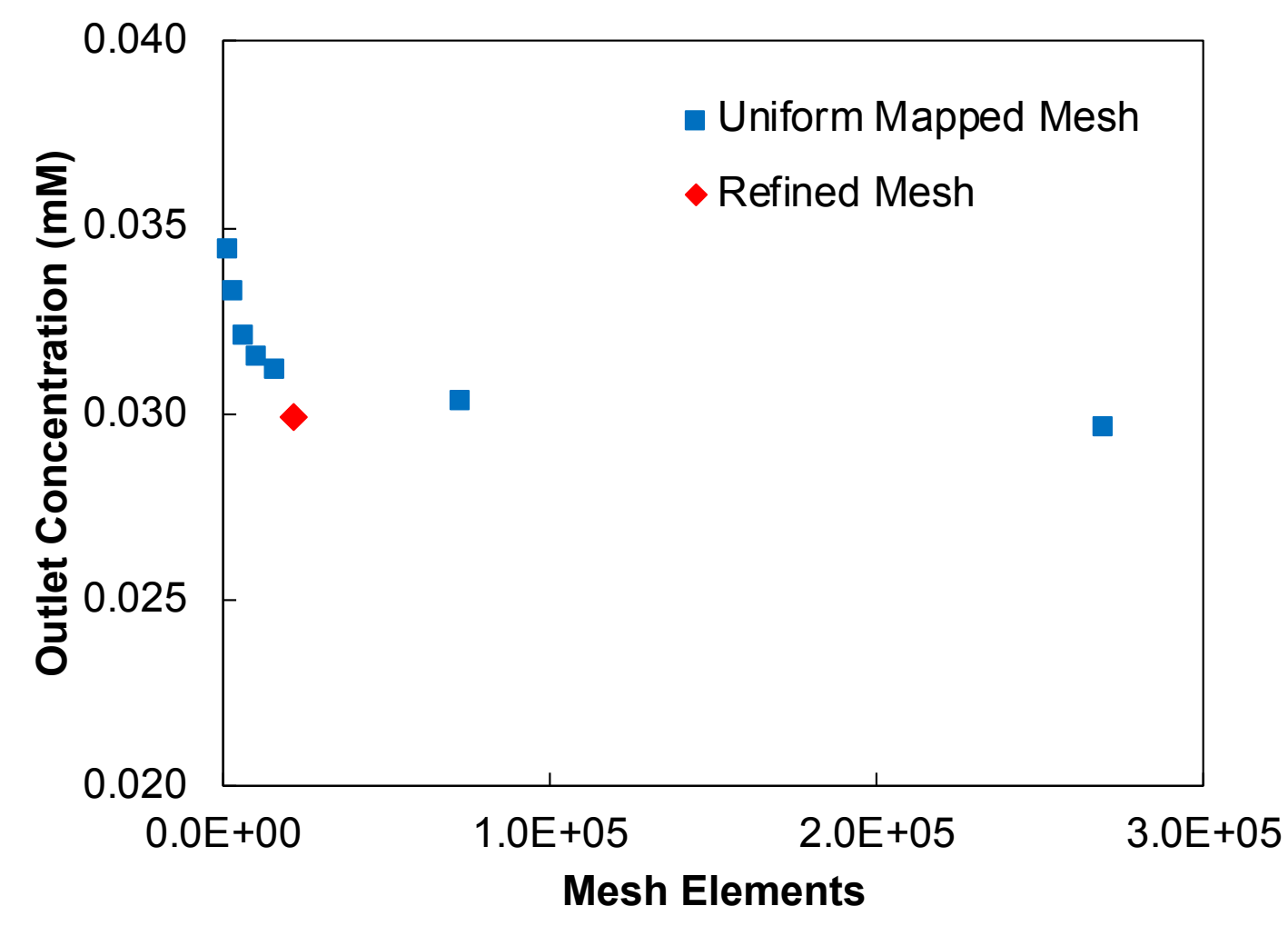

Figure S4. The outlet organic phase concentration converges with increasing uniform mesh density. Use of the refined mesh minimizes error and computation time.

\section{Supported Liquid Membrane Numerical Model}

The supported liquid membrane (SLM) numerical transport model geometry referred to in the body of this manuscript is shown in Figure S5 for a module with a $400 \mu \mathrm{m}$ channel depth $\left(\mathrm{h}_{\mathrm{c}}\right)$ and a $80 \mu \mathrm{m}$ thick membrane $\left(\mathrm{h}_{\mathrm{m}}\right)$ with $74 \%$ porosity $(\varepsilon)$. The diffusion coefficient in the membrane was calculated by multiplying the organic phase diffusion coefficient, $\mathrm{D}_{\text {org }}$, by the membrane porosity divided by the tortuosity. The tortuosity was estimated to be $(2-\varepsilon)^{2} / \varepsilon=2.15$, in a relationship developed by Iversen et al. The boundary and initial conditions used in the model are provided in Table S3. The exact form of the concentration-dependent diffusion coefficient used to model kinetically limited interfacial solute transfer can be derived as described for the droplet numerical model. 

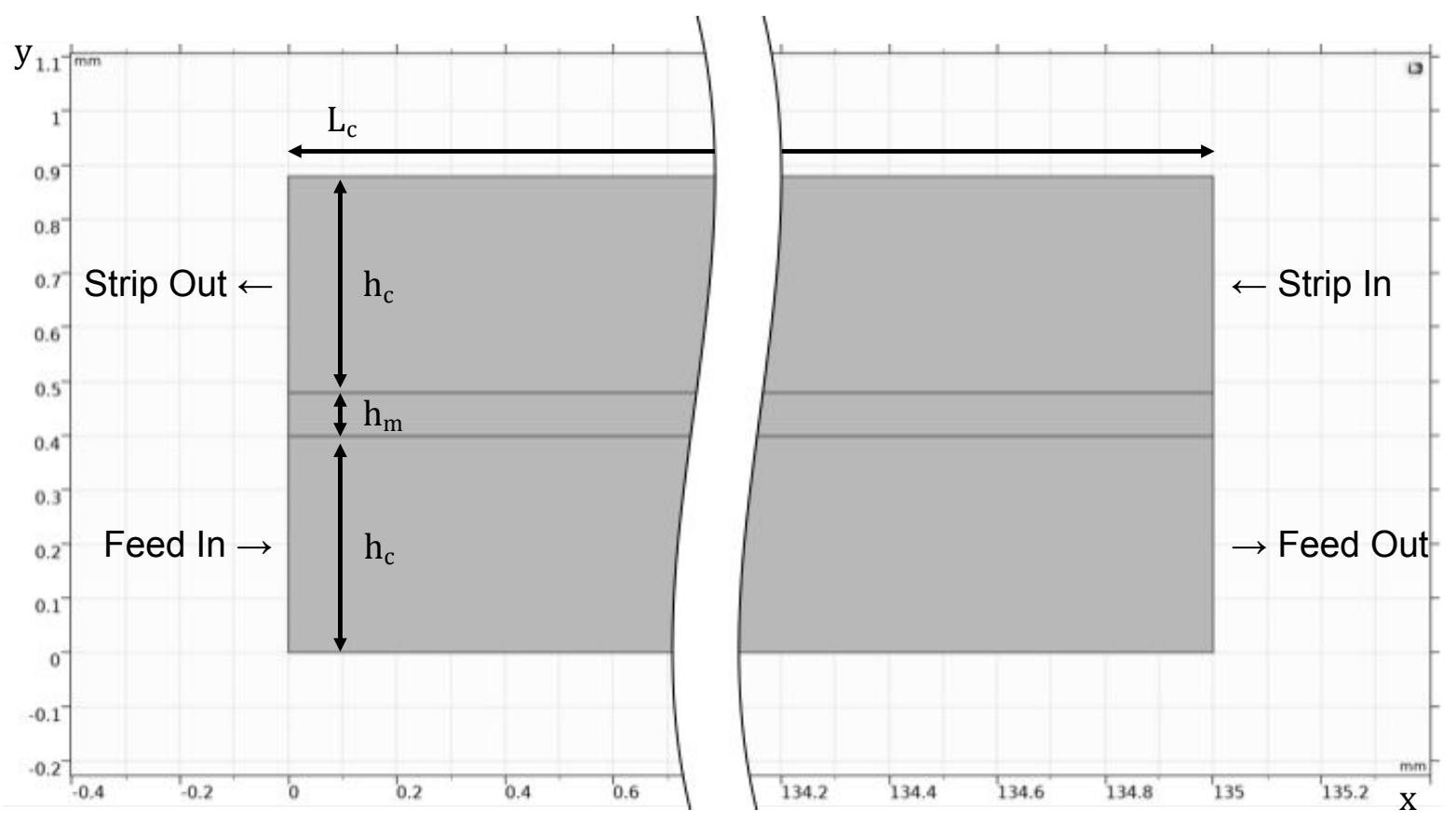

Figure S5. Geometry for the 2D SLM model (400 $\mu \mathrm{m}$ channel depth shown). The value for $L_{c}$ was calculated by multiplying the length of the channels in the module by their number (15 mm and 9 , respectively). 
Table S3. SLM numerical model boundary and initial conditions. $C$ is concentration, $P$ is pressure, $\vec{J}$ is flux, $\vec{v}$ is velocity, u is up, dis down.

\begin{tabular}{|c|c|c|}
\hline $\begin{array}{ll}\text { Boundary } & \text { Condition } \\
\text { Description } & \end{array}$ & Limits & Condition \\
\hline $\begin{array}{l}\text { Feed inlet concentration and } \\
\text { velocity }\end{array}$ & $x=0,0 \leq y \leq h_{c}$ & $C_{0}=1 \mathrm{mM}, \vec{v}=$ varied \\
\hline $\begin{array}{l}\text { Strip inlet concentration and } \\
\text { velocity }\end{array}$ & $x=L_{c}, h_{c}+h_{m} \leq y \leq 2 h_{c}+h_{m}$ & $C_{0}=0 \mathrm{mM}, \vec{v}=$ varied \\
\hline $\begin{array}{l}\text { Feed and strip outlet gauge } \\
\text { pressure }\end{array}$ & $\begin{array}{l}\qquad x=L_{c}, 0 \leq y \leq h_{c} \\
\text { and } \\
\qquad x=0, h_{c}+h_{m} \leq y \leq 2 h_{c}+h_{m}\end{array}$ & $P=0 P a$ \\
\hline $\begin{array}{l}\text { No slip condition at walls and } \\
\text { interfaces }\end{array}$ & 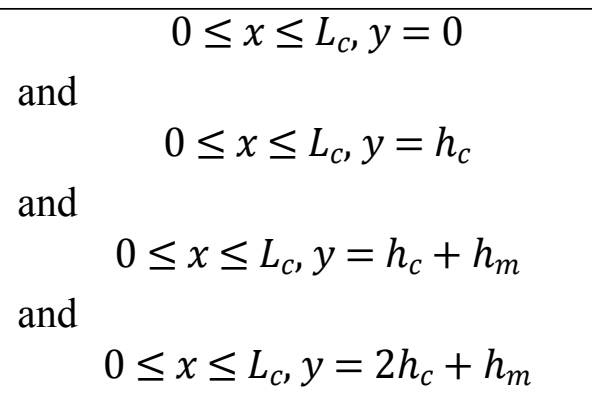 & $\vec{v}=0$ \\
\hline Stagnant membrane & $0 \leq x \leq L_{c}, h_{c}<y<h_{c}+h_{m}$ & $\vec{v}=0$ \\
\hline $\begin{array}{l}\text { Thin diffusion barrier at } \\
\text { interfaces* }\end{array}$ & $\begin{array}{c}0 \leq x \leq L_{c}, y=h_{c} \\
\text { and } \\
0 \leq x \leq L_{c}, y=h_{c}+h_{m}\end{array}$ & $\begin{array}{l}\vec{J}=\frac{D}{5[n m]}\left(C_{u}-C_{d}\right) \\
D=f\left(k_{o a}, k_{a o}, C_{u}, C_{d}\right)\end{array}$ \\
\hline No flux condition at walls & $\begin{array}{c}0 \leq x \leq L_{c}, y=0 \\
\text { and } \\
0 \leq x \leq L_{c}, y=2 h_{c}+h_{m}\end{array}$ & $\vec{J}=0$ \\
\hline
\end{tabular}

* Refer to COMSOL documentation for details about the thin diffusion barrier boundary condition and up/down notation at interfaces. 


\section{SLM Dependence on Kinetic Rate Constants}

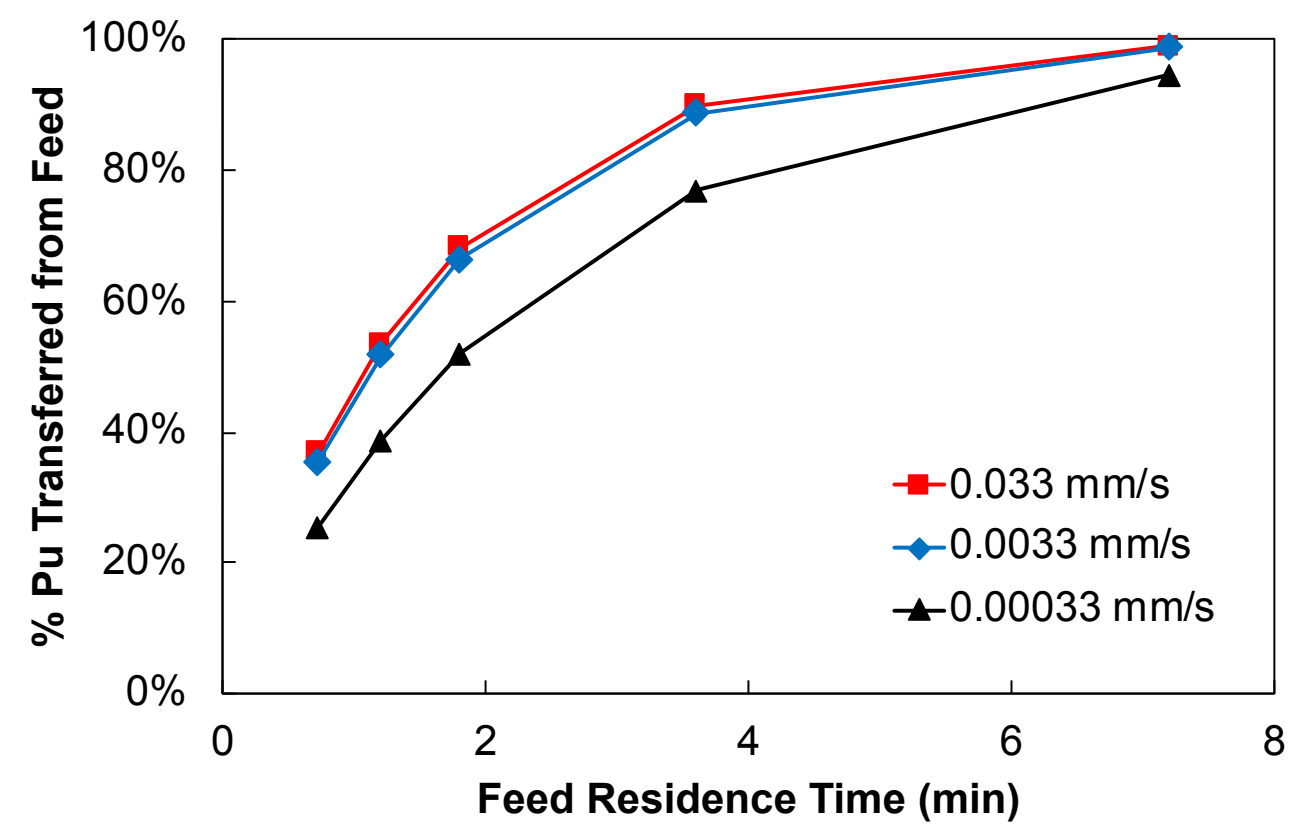

Figure S6. The change in the extent of Pu extraction with changing forward extraction rate constant on the strip side of the SLM, $k_{o a}$, is small when $k_{\text {oa }}$ is increased by an order of magnitude, but more pronounced when it is decreased by an order of magnitude.

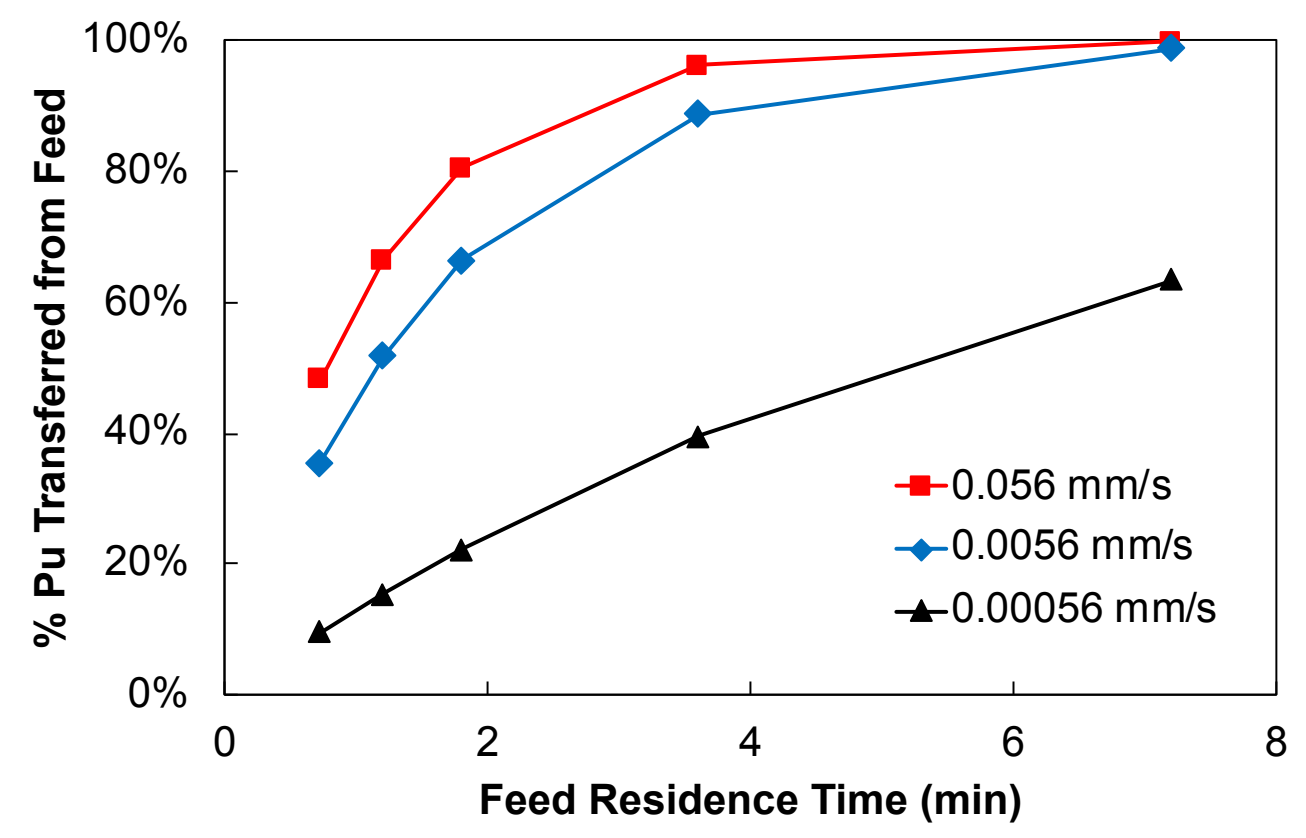

Figure S7. The change in the extent of Pu extraction with changing forward extraction rate constant on the extraction side of the SLM, $k_{a o}$, is large when $k_{a o}$ is increased or decreased by an order of magnitude. 


\section{Incomplete Phase Separation Error Analysis}

When very high or very low distribution ratios are measured in liquid-liquid extraction systems, small amounts of cross contamination between the phases can result in large errors in the value of the measured distribution ratio. For example, if the true distribution ratio for a system is 200 (corresponding to $99.5 \%$ extraction) and $0.5 \%$ of the aqueous phase remains entrained in the organic phase due to incomplete phase separation, the measured distribution ratio will be 100 . This small amount of entrainment contributes substantial error to the distribution ratio measurement. However, because interfacial rate constant measurements use multiple data points collected away from equilibrium conditions, the impact of incomplete phase separation on the uncertainty of the rate constant measurement is far less than for distribution ratio measurements.

If the interfacial rate constant is measured for a system with $5 \%$ entrainment of the aqueous phase in the organic phase and an equilibrium distribution of $99.5 \%$ of the metal into the aqueous phase (stripping conditions), the apparent organic phase concentration would be $95 \% * 0.5+5 \% * 99.5=$ 5.45 , or 10.9 times the actual amount. However, because this is a kinetic experiment, this extreme condition never occurs. The greatest amount of aqueous phase $\mathrm{Pu}$ observed in the experiments performed in this work under stripping conditions is about $62 \%$, corresponding to $95 \% * 38+$ $5 \% * 62=39.2$, or 1.03 times the actual amount. Consequently, the impact of water entrainment in the organic phase on individual measurements is very small, with virtually no impact on the fitted interfacial rate constants. Figure 1 compares the results that would be obtained at 5\% entrainment with experimental values. Table 1 shows the impact of varying amounts of aqueous entrainment on the fitted interfacial rate constants.

If the interfacial rate constant is measured with $5 \%$ entrainment of the organic phase in the aqueous phase and an equilibrium distribution of $99.5 \%$ of the metal into the aqueous phase (stripping conditions), there is a much greater potential for problems because the smallest observed amount of $\mathrm{Pu}$ stripped is about $2 \%$. The concentration difference between the two phases is large and has a greater impact on the observed $\mathrm{Pu}$ concentration than in the opposite condition. Replicating the calculation above, the measured amount of $\mathrm{Pu}$ in the aqueous phase at $5 \%$ entrainment would be $95 \% * 2+5 \% * 98=6.8$, or 3.4 times the actual amount. The greater impact of organic entrainment compared with aqueous entrainment is evident in Figure 2. The addition of a small amount of high concentration organic to the aqueous phase leads to a notable increase in the percent Pu stripped compared with the true amount. The error in the fitted interfacial rate constants at various percentages of organic phase entrainment is provided in Table 2.

A reasonable estimate of the smallest amount of entrained liquid that would be detectable visually as cloudiness and the visible formation of a small separate phase in a sample is $0.5 \%$, corresponding to $25 \mu \mathrm{L}$ in a $5 \mathrm{~mL}$ sample. This amount of entrainment corresponds to a less than $1 \%$ error in interfacial rate constant, which is small compared with the uncertainty introduced by sample preparation and counting (estimated at 5\%). The above analysis provides a basis for a heuristic that should be followed droplet extraction experiments to minimize the error in the measured interfacial rate constants due to incomplete phase separation when the phases are visibly clear: residence times should be varied so that the percent metal extracted or stripped is between roughly 2 and $98 \%$, and samples the greatest range between those values as possible. 


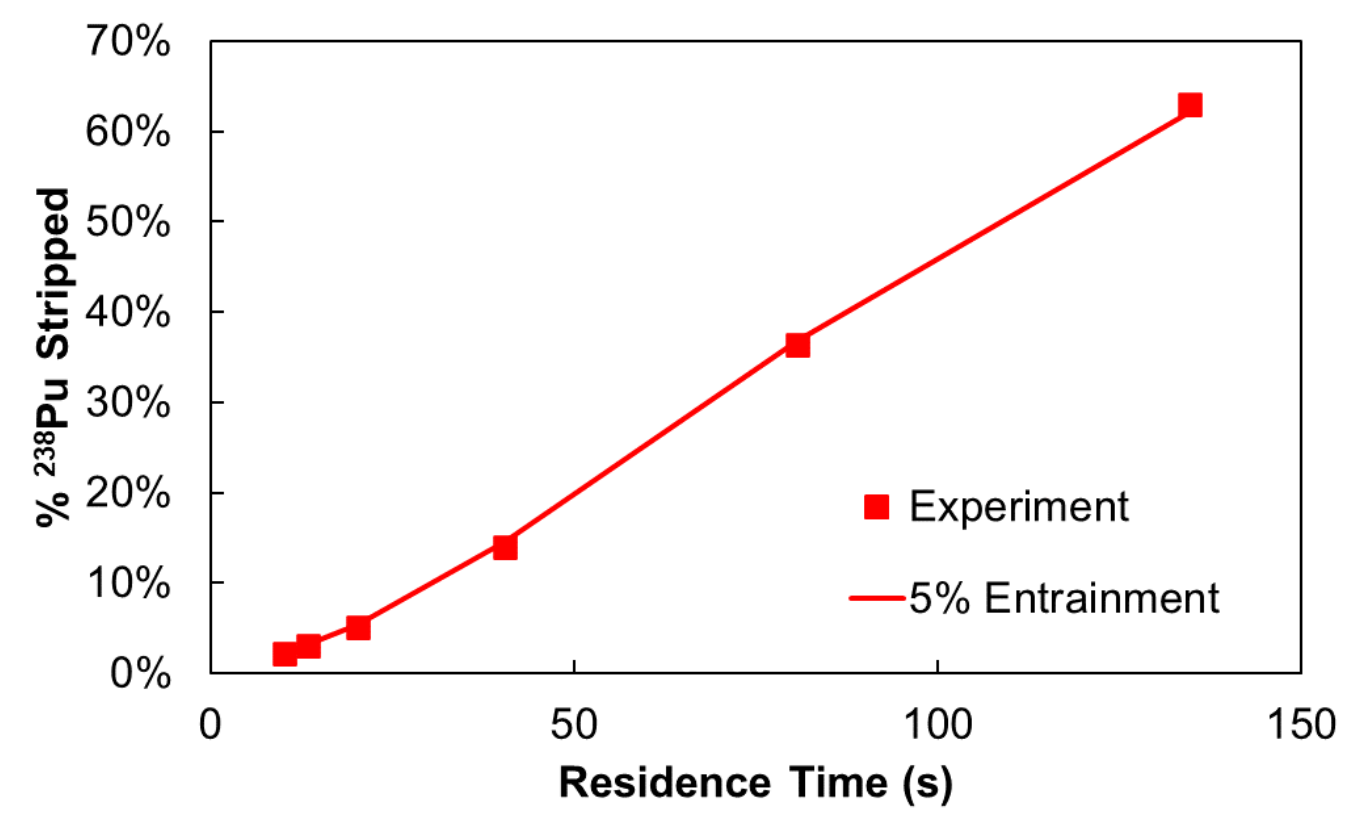

Figure S8. When 5\% of the aqueous phase is entrained in the organic phase during kinetic constant measurements, the greatest impact is at high residence times due to dilution of the organic phase by the aqueous phase.

Table S4. The relative error in the fitted interfacial rate constants is very low for all water entrainment conditions.

\begin{tabular}{|c|c|c|c|c|c|}
\hline $\begin{array}{c}\text { Water in } 5 \\
\text { mL Organic } \\
(\mu L)\end{array}$ & $\begin{array}{c}\text { Percent } \\
\text { Entrainment } \\
\end{array}$ & $\mathbf{k}_{\mathrm{ao}}(\mathrm{mm} / \mathrm{s})$ & $\mathbf{k}_{0 \mathrm{a}}(\mathrm{mm} / \mathrm{s})$ & $\begin{array}{c}\text { Rel. \% Error } \\
\text { in } k_{\mathrm{ao}}\end{array}$ & $\begin{array}{c}\text { Rel. \% Error } \\
\text { in } \mathbf{k}_{\mathbf{0 a}}\end{array}$ \\
\hline 0 & 0 & 8.04E-06 & $3.26 \mathrm{E}-03$ & $0.0 \%$ & $0.0 \%$ \\
\hline 25 & $0.5 \%$ & $8.04 \mathrm{E}-06$ & $3.26 \mathrm{E}-03$ & $0.0 \%$ & $0.0 \%$ \\
\hline 50 & $1 \%$ & $8.04 \mathrm{E}-06$ & $3.26 \mathrm{E}-03$ & $0.0 \%$ & $0.0 \%$ \\
\hline 250 & $5 \%$ & $8.04 \mathrm{E}-06$ & $3.26 \mathrm{E}-03$ & $0.0 \%$ & $0.0 \%$ \\
\hline 500 & $10 \%$ & $8.05 \mathrm{E}-06$ & $3.26 \mathrm{E}-03$ & $0.1 \%$ & $0.1 \%$ \\
\hline
\end{tabular}




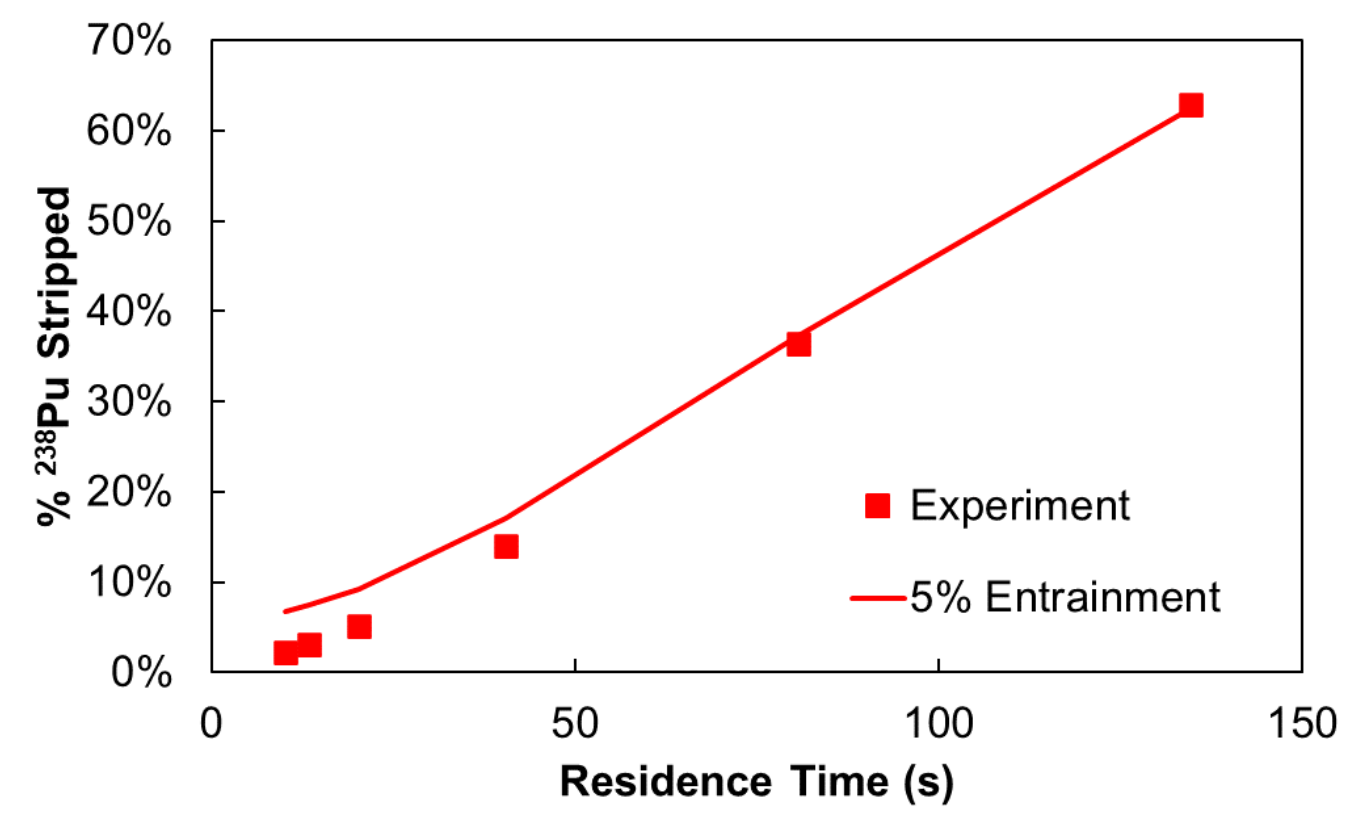

Figure 9. When 5\% of the organic phase is entrained in the aqueous phase during kinetic constant measurements, the greatest impact is at low residence times due to transfer of a small amount of high concentration organic phase to the dilute aqueous.

Table 5. The relative error in the fitted interfacial rate constants increases with increasing entrainment of the organic phase in the aqueous phase.

\begin{tabular}{|c|c|c|c|c|c|}
\hline $\begin{array}{c}\text { Organic in } 5 \\
\text { mL Water } \\
(\mu \mathrm{L})\end{array}$ & $\begin{array}{c}\text { Percent } \\
\text { Entrainment } \\
\end{array}$ & $\mathbf{k}_{\mathrm{ao}}(\mathrm{mm} / \mathrm{s})$ & $\mathbf{k}_{\mathbf{0 a}}(\mathrm{mm} / \mathrm{s})$ & $\begin{array}{c}\text { Rel. \% Error } \\
\text { in } k_{\mathrm{a} 0}\end{array}$ & $\begin{array}{c}\text { Rel. \% Error } \\
\text { in } \mathbf{k}_{\mathbf{0 a}} \\
\end{array}$ \\
\hline 0 & 0 & 8.04E-06 & $3.26 \mathrm{E}-03$ & $0.0 \%$ & $0.0 \%$ \\
\hline 25 & $0.5 \%$ & 8.09E-06 & $3.28 \mathrm{E}-03$ & $0.6 \%$ & $0.6 \%$ \\
\hline 50 & $1 \%$ & $8.14 \mathrm{E}-06$ & $3.30 \mathrm{E}-03$ & $1.2 \%$ & $1.2 \%$ \\
\hline 250 & $5 \%$ & $8.53 \mathrm{E}-06$ & $3.45 \mathrm{E}-03$ & $6.1 \%$ & $6.1 \%$ \\
\hline 500 & $10 \%$ & $9.02 \mathrm{E}-06$ & $3.65 \mathrm{E}-03$ & $12.2 \%$ & $12.2 \%$ \\
\hline
\end{tabular}




\section{References}

Iversen, S. B.; Bhatia, V. K.; Dam-Johansen, K.; Jonsson, G. Characterization of Microporous Membranes for Use in Membrane Contactors. J. Memb. Sci. 1997, 130 (1), 205-217.

Servis, A. G.; Parsons-Davis, T.; Moody, K. J.; Gharibyan, N. 3D Printed Microfluidic Supported Liquid Membrane Module for Radionuclide Separations. Ind. Eng. Chem. Res. 2021, 60 (1), 629-638.

Wang, K.; Luo, G. Microflow Extraction: A Review of Recent Development. Chem. Eng. Sci. 2017, 169, 18-33. 